\title{
Board 54: Do engineering students care about the social good?
}

\section{Dr. Denise Wilson, University of Washington}

Denise Wilson is a professor of electrical engineering at the University of Washington, Seattle. Her research interests in engineering education focus on the role of self-efficacy, belonging, and other noncognitive aspects of the student experience on engagement, success, and persistence and on effective methods for teaching global issues such as those pertaining to sustainability.

\section{Emily Parry}

Joanna Wright, University of Washington

Joanna Wright is an M.Ed. student in Learning Sciences and Human Development at the University of Washington, Seattle. Her education research interests span early childhood through higher education, with a focus on the impact of pedagogical practices and contexts on learning and development.

\section{Lauren Summers, University of Washington}

Lauren Summers is a doctoral student in the College of Education at the University of Washington, Seattle. Her research interests focus on the potential roles of socioeconomic status, ethnicity, gender, and other political identifiers in determining undergraduate engagement across a variety of majors, including engineering. 


\title{
Do engineering students care about the social good?
}

\begin{abstract}
This research paper explores the beliefs that students hold around major social issues including social justice, global disparities, and the role of technology in alleviating injustice. In a survey completed by almost 400 students from four different areas of study at a major public university, scores from three subscales of social responsibility beliefs show that education and environmental studies majors express stronger beliefs about global disparities than engineering students. Significant differences among environmental, education, business, and engineering majors also emerged regarding beliefs about the potential for technology to support solutions to major social issues. In contrast, no significant difference among engineering, education, environmental studies, and business majors emerged in terms of beliefs about social justice.

Depending on the model, sustainability either embodies social responsibility within global environmental limits or overlaps social responsibility with economic and environmental concerns about providing the next generation with opportunities comparable to the present generation. Regardless of which model is accepted, sustainable development includes critical issues of social responsibility, but can also be presented in the context of specific challenges (e.g. resource scarcity, sustainable energy). These allow us to study how social responsibility extends from beliefs and knowledge to responsibility for supporting sustainable development. To this end, three additional scales oriented around the specific issues of sustainability and sustainable development are also addressed in this study to examine the inter-relationships among beliefs, knowledge, and responsibility. A hierarchical linear regression model was constructed to study these inter-relationships using student major, four belief subscales, and one knowledge subscale as independent variables, and responsibility for sustainable development as a dependent variable. Results showed that beliefs about social justice and sustainability as well as knowledge about sustainability significantly predicted responsibility for sustainability. However, beliefs about global disparities and the role of technology did not predict this outcome. No interactions between student major and beliefs or knowledge were found, thereby suggesting that these relationships among beliefs, knowledge, and responsibility remain true across area of study.

In conjunction with existing studies, these results support the public perception that engineers are less concerned with social issues, but also promote the idea that education targeted toward developing beliefs and improving knowledge can potentially impact the level of responsibility for social issues adopted by students in school and subsequently in their chosen professions.
\end{abstract}




\section{Introduction}

At least 10 of the 14 grand challenges of engineering defined by the National Academy of Engineering address major social issues related to global agriculture, water supply, healthcare and medicine, climate change, urban infrastructure, and nuclear conflict [1]. In order to comprehensively address these grand challenges, it is essential for engineers to be invested in the social good. To this end, many engineering students recognize their disciplines may have a significant impact on society [2] and report being moderately motivated by social good to enter engineering [3]. However, previous research has also shown that many students enter engineering majors for reasons other than the social good, including flexibility of major and career opportunities [4], interest in math and science, desire to build things [3], inherent enjoyment [3], and financial benefits [3]. Not surprisingly, once in the workforce, many engineers are subsequently motivated to remain in engineering by a love for technology, or a desire to solve puzzles and think conceptually [5], [6]. Although many of these workforce studies are qualitative, with generalizability yet to be proven, it appears that the strongest and most powerful factors that motivate engineers to persist in the workforce are inconsistent with what drives the major challenges that face engineering today. Given the importance of these grand challenges [1], engineering must attract individuals who are invested in the benefits and outcomes of meeting those challenges.

Among women engineers, motivation and opportunity to pursue social good are especially important. Although key predictors of female retention in the engineering workforce include high self-efficacy, strong engineering identity, and an intrinsic love for engineering and its challenges [5][7], women often leave due to opportunities outside of engineering to pursue social good [5][8]. Thus, developing awareness of and providing opportunities to do social good in engineering, both during college and professionally, may be especially important for retaining women in the engineering workforce.

Despite the importance of concern for the social good in addressing the grand challenges and supporting gender parity in engineering, the public believes that engineers are less engaged in societal concerns than scientists [9] and that engineers contributes less to society than both scientists and teachers [10]. The primary goal of this study is to gain insight into whether or not these public perceptions are about the profession or the person. Do engineers care less about the social good or is the perceived impact of engineering work on society simply lower than that associated with other types of work?

\section{Background}

In order to analyze how engineering students differ from students in other disciplines, this study looks at the general beliefs that students hold regarding social responsibility as well as their specific beliefs, knowledge, and professional responsibility for contributing to society through sustainable development.

\section{Social Responsibility}

Social responsibility is a term that has many dimensions and has been interpreted through multiple lenses. In this study, social responsibility is defined “... as the perceived level of interdependence and social concern to others, to society and to the environment." [11, p. 3] and 
includes beliefs about global injustice and disparities, empathy for those less fortunate, and global interconnectedness.

While this study focuses on beliefs regarding social responsibility, other studies have looked specifically at the sense of obligation engineering students have to be socially responsible. Canney and Bielefeldt [12] examined multiple dimensions of such social obligation in a study of 1,698 college students across five institutions that investigated potential differences among three engineering disciplines (civil, environmental, and mechanical engineering) and across ranks (first year, senior year, and graduate level). The study found that both male and female environmental engineering students had the strongest beliefs about personal and professional obligations to serve society. However, the greatest differences occurred for first-year students, suggesting that a culture of disengagement [13] diminishes students' sense of social responsibility and their positive attitudes towards being agents of change. Furthermore, the results suggested that differences by major were driven by self-selection into the major rather than the education provided within the major [12]. If, by self-selection, individuals with strong social responsibility beliefs choose environmental engineering for opportunities to do social good, this may partially explain the significant growth of this field compared to other engineering disciplines [14]. It may also help explain why environmental engineering has attracted women at greater rates than other engineering fields, as demonstrated by the near disappearance of the gender gap in environmental engineering among bachelor's degrees in the United States [15].

Other studies have viewed social responsibility through the lens of corporate social responsibility (CSR). For example, in a quantitative study of Hungarian business students, women were found to be more sensitive to corporate social responsibility than men. And, the global issues that these students found most pressing were starvation, climate change, and the depletion of energy resources [16]. Another qualitative study of students in Portugal found that while CSR curricula did affect student views, there was a strong need for more coherence in how social responsibility was integrated into the curriculum in order to effectively put social responsibility and sustainability in the center of the college graduate's radar screen [17].

Still other studies have focused on curricular strategies to increase social responsibility and other global citizenship measures. For instance, Tarrant et al. [18] found that shifting the focus of a course to a critical social issue (sustainability) did not in and of itself guarantee an increase in social responsibility. However, offering sustainability-focused courses abroad did produce a significant increase in attention to social responsibility and global citizenry [18].

Few studies have investigated how engineering students differ from students in other disciplines in their beliefs about social responsibility. However, a large study did look at social agency outcomes, which are similar, but not identical, to social responsibility. In this extensive quantitative study [19] of 6,100 college students in the U.S., majoring in STEM disciplines was significantly and negatively associated with social agency outcomes, including promoting racial understanding, helping those in difficulty, and keeping up with political news. Furthermore, STEM students thought working for social change was less important than their individual career goals [19]. But, the sense of social agency these students reported was significantly and positively influenced by participation in cocurricular activities, including cultural clubs, academic clubs, professional associations, and undergraduate research [20]. Additionally, for 
under-represented students of color, intentions to work for social change were significantly greater than for other students within STEM.

Beliefs alone, however, are not sufficient to guarantee or empower action among students as they embark on their careers. To complement measures designed to capture general beliefs regarding social responsibility, this study also includes additional measures related to global sustainability in order to understand whether or not beliefs and knowledge regarding a specific societal challenge predict a student's sense of professional responsibility for addressing that challenge.

\section{Global Sustainability}

Some may argue that social responsibility is a single pillar in the realm of global sustainability as in the (social, economic, environmental) triple bottom line (TBL) first proposed by the Brundtland commission in 1987 in Our Common Future [21]. But, others argue that sustainable development is separate and complementary to social responsibility by addressing critical economic and environmental issues associated with global growth. Viewing sustainability as a series of environmental issues is consistent with traditional ideas of sustainability that individuals and organizations should minimize their impact on the environment in all that they do.

Consistent with the TBL, economic sustainability focuses on economic growth without harming others, particularly in rapidly changing developing countries and communities. Meanwhile, social sustainability emphasizes social responsibility so that all actions either improve the lives of others or at least do not harm others [21], [22]. Clearly, social, environmental, and economic sustainability interconnect with one another in many mutually reinforcing ways, whether nested inside one another or overlapping like a Venn diagram [23], [24]. Thus, understanding an individual's perspective on one pillar can provide insight into the remaining two pillars.

Previous research suggests that engineering students identify sustainability in traditional terms of environmental impacts rather than more comprehensive TBL (triple bottom line) terms. Engineering students' understanding of sustainability seem to be largely restricted to ecological or environmental impacts, and they neglect the social and economic pillars [25], [26] of the TBL. These limited views of sustainability have been compounded by individual student resistance at both undergraduate and graduate levels to the integration of sustainability topics into engineering courses. This pattern seems to correspond with beliefs that sustainability is unrelated to the technical content in engineering curricula and is outside the scope of engineering education [27], [28].

Given the disproportionate importance that engineering students place on environmental issues, evaluating beliefs, knowledge, and responsibility for sustainability in environmental terms has merit. Thus, the measures of beliefs about, knowledge of, and responsibility for sustainable development used in this study focus on environmental impact.

\section{Research Questions}

Our research is guided by two research questions, both focused on understanding how engineering students differ from those in other disciplines in their beliefs about, knowledge of, and responsibility for the social good. 


\section{Research Question \#1:}

Do undergraduates in engineering express different levels of social responsibility from students in other disciplines (business, education, environmental studies)?

In conjunction with other studies that focus on differences between different branches of engineering [12] and between engineering and other STEM fields [19], this study can offer additional insight into where social responsibility or sustainability should be integrated into the curriculum. It can also help to dispel or confirm public perception that engineers may be less concerned with social issues than scientists and other professionals.

\section{Research Question \#2:}

How do what students believe and what they know about critical issues in global sustainability predict their sense of responsibility for global sustainability?

This question offers some insight into whether providing content knowledge (regarding sustainability topics such as resource scarcity and sustainable energy) or navigating changes in beliefs regarding social responsibility and sustainability impacts a student's sense of responsibility for social and environmental issues of global importance. Providing insight into these questions may help to tailor curricular and cocurricular interventions by addressing which beliefs or knowledge make the most difference in producing socially and environmentally responsible graduates.

\section{Methods}

This study is quantitative, drawing on surveys completed by students in four different types of majors at a single large public research institution.

\section{Participants}

The population examined by this study consisted of 399 undergraduate students who had chosen majors associated with business (21\%), education (10\%), engineering and computer science $(59 \%)$, or environmental studies $(10 \%)$. Approximately $41 \%$ of the sample was female, and the self-reported ethnicity was primarily White (44\%) and Asian (43\%). Within engineering, the majors most represented in this population were electrical engineering $(58.9 \%)$ and mechanical engineering (31.6\%), which together make up 35\% [14] of the total engineering degrees granted in the United States. Characteristics of the study population are summarized in Table 1.

\section{Procedures}

IRB (Internal Review Board) approval was obtained by the investigating institution to recruit, incentivize, and survey students via convenience sampling. Undergraduate participants were recruited over four academic terms. In engineering, participants were recruited from core engineering classes at the junior and senior levels and incentivized by providing a nominal amount of extra credit for the course in which they were recruited. In other majors, participants were randomly recruited by e-mail from department or college listservs and offered an Amazon gift card in exchange for survey completion. Participation in the study was voluntary, and students were assured their survey responses would remain confidential. All students completed an electronic survey online and outside of class. Surveys were collected with identifying information so that duplicate surveys could be removed before aggregating data for analysis. All results were cross-sectional. In the survey, students reported their perceptions of various items related to social responsibility, global competence, global civic engagement, consumer 
responsibility, sustainability, and professional identity as well as multiple demographic items. The survey also included affective measures assessing self-efficacy, task value, belonging, and job values that may play a role in mediating how students develop their views of sustainability or sense of social responsibility and global citizenship during their undergraduate years.

Table 1: Characteristics of the Study Population

\begin{tabular}{|l|c|c|c|}
\hline & Women & Men & Total \\
\hline Total & 164 & 235 & 399 \\
\hline Type of Major & & & \\
Business & 54 & 32 & 86 \\
Education & 35 & 5 & 40 \\
Engineering and Computer Science & 45 & 190 & 235 \\
Environmental Studies & 30 & 8 & 38 \\
\hline Race & & & \\
Asian & 73 & 99 & 172 \\
Black/African American & 2 & 5 & 7 \\
Latino & 10 & 0 & 10 \\
White & 70 & 105 & 175 \\
Other & 6 & 9 & 14 \\
\hline U.S. Citizenship & & & \\
U.S. Citizen or Permanent Resident & 142 & 189 & 331 \\
International & 21 & 44 & 65 \\
\hline Age (Mean) & 21.8 & 22.1 & 22.0 \\
\hline GPA (Mean) & 3.45 & 3.52 & 3.50 \\
\hline
\end{tabular}

\section{Instruments}

The part of the study reported in this paper focuses on a single demographic measure (discipline), four measures of beliefs, one measure of knowledge, and one measure of responsibility. The three subscales related to social responsibility and three scales related to global sustainability have been used in previous studies [11][29] and showed good validity and reliability. All items were evaluated on a 5-point Likert scale and are described and listed by category in Table 2 along with sample items and Cronbach's reliability coefficients.

\section{Data Analysis}

The data were analyzed using SPSS 19 to compute descriptive statistics, test the reliability of the six subscales, conduct analyses of variance (ANOVA) by field of study, and construct the linear regression models for analysis. In the first set of analyses, differences in the six subscales were studied across discipline using a series of one-way ANOVAs. Hierarchical linear regression models were then used to understand how discipline, beliefs, and knowledge predicted responsibility. For the regression models, type of major was effect coded as summarized in Table 3.

Bivariate Pearson correlations between the five dependent variables were also analyzed during preliminary analyses to determine whether any of these measures potentially measured the same thing. All correlations were below .5 except for the correlation between social justice and sustainability beliefs, which was slightly higher (.57). All five variables were retained because 
regression models using sustainability and social justice beliefs showed that the interactions between the two variables were not significant.

Table 2: Social Responsibility and Global Sustainability Subscales

\begin{tabular}{lll}
\hline Primary Scale & Subscale & Sample Item \\
\hline & $\begin{array}{l}\text { Global Disparity (Beliefs): } \\
\alpha=0.61\end{array}$ & $\begin{array}{l}\text { I think that most people around the world get what } \\
\text { they are entitled to have. }\end{array}$ \\
$\begin{array}{l}\text { Social } \\
\text { Responsibility }\end{array}$ & $\begin{array}{l}\text { Social Justice (Beliefs): } \\
\text { Ro one country or group of people should dominate } \\
\text { and exploit others in the world. }\end{array}$ \\
& $\begin{array}{l}\text { Role of Technology } \\
\text { (Beliefs): } \alpha=0.73\end{array}$ & $\begin{array}{l}\text { Science and technology help give more opportunities } \\
\text { to poor or disadvantaged people. }\end{array}$ \\
\cline { 2 - 3 } Beliefs about Global & I believe that resource scarcity impacts global \\
Sustainability: $\alpha=0.86$ & sustainability. \\
Global & Knowledge of Global & I know a great deal about sustainable energy. \\
Sustainability & $\begin{array}{l}\text { Sustainability: } \alpha=0.85 \\
\text { Responsibility for }\end{array}$ & $\begin{array}{l}\text { As }<\text { an engineer }>\text { I feel responsible for addressing } \\
\text { global resource scarcity in my work/career. }\end{array}$
\end{tabular}

Table 3: Effect Coding of Independent Variables for Linear Regression Models

\begin{tabular}{|c|c|c|c|}
\hline Characteristic & $\begin{array}{c}\text { Variable } \\
\text { Name(s) }\end{array}$ & \multicolumn{2}{|c|}{ Effect Coding } \\
\hline \multirow{2}{*}{ Type of Major } & $\begin{array}{c}\text { Business } \\
\text { Education } \\
\text { Environment }\end{array}$ & $\begin{array}{c}\text { Engineering } \\
\text { Business } \\
\text { Education } \\
\text { Environment }\end{array}$ & $\begin{array}{c}\text { Business }=-1 \text {; Education }=-1 \text {; Environment }=-1 \\
\text { Business }=+1 \text {; Education }=0 \text {; Environment }=0 \\
\text { Business }=0 \text {; Education }=+1 \text {; Environment }=0 \\
\text { Business }=0 \text {; Education }=0 \text {; Environment }=+1\end{array}$ \\
\hline
\end{tabular}

\section{Results \& Discussion}

Results were analyzed using one-way ANOVA to understand differences among the four types of majors (Research Question \#1), and a hierarchical linear regression model to understand if and how the four sets of beliefs (social justice, global disparities, the role of technology, and sustainability) predicted an individual's sense of responsibility to address major global issues (Research Question \#2).

\section{Research Question \#1:}

Do undergraduates in engineering express different levels of social responsibility from students in other disciplines (business, education, environmental studies)?

Descriptive statistics for the three subscales representing beliefs about social responsibility are summarized in Table 4. Significant differences were found among the four types of majors for two of the three belief scales: global disparities and the role of technology, although the strength of the differences were small for the role of technology with an effect size of 0.024. The strength 
of the differences by area of study within global disparities was larger (0.045) but did not meet the medium effect size threshold of 0.06 established by Cohen [31].

Post-hoc comparisons using the Bonferroni correction indicated that the mean global disparities score for environmental studies majors and education majors was significantly higher than the mean score for engineering majors. No other statistically significant differences emerged in these pairwise comparisons.

Table 4: Descriptive Statistics for Social Responsibility Beliefs

\begin{tabular}{|l|c|c|c|}
\hline \multirow{2}{*}{ Type of Major } & \multicolumn{3}{|c|}{ Mean (Standard Deviation) } \\
\cline { 2 - 4 } & \multicolumn{3}{|c|}{ Beliefs } \\
\cline { 2 - 4 } & Social Justice & Global Disparities & Role of Technology \\
\hline \multirow{2}{*}{ All } & $N=399$ & $N=399$ & $N=399$ \\
& $15.4(3.35)$ & $11.3(2.45)$ & $10.3(2.47)$ \\
\hline \multirow{2}{*}{ Business } & $N=86$ & $N=86$ & $N=86$ \\
& $15.3(3.17)$ & $11.2(2.58)$ & $10.5(2.55)$ \\
\hline \multirow{2}{*}{ Education } & $N=40$ & $N=40$ & $N=40$ \\
& $16.1(3.32)$ & $12.5(2.03)$ & $9.55(2.27)$ \\
\hline \multirow{2}{*}{ Engineering } & $N=235$ & $N=235$ & $10.5(2.42)$ \\
\hline \multirow{2}{*}{ Environment } & $15.1(3.47)$ & $10.9(2.43)$ & $N=38$ \\
& $N=38$ & $N=38$ & $9.58(2.59)$ \\
\hline Maximum Score & $16.3(2.84)$ & $12.1(2.21)$ & 3 \\
\hline Minimum Score & 20 & 15 & $\mathrm{~F}(3,395)=3.21$ \\
\hline ANOVA Results & $\mathrm{F}(3,395)=2.01$ & $\mathrm{~F}(3,395)=6.28$ & $p=0.023 *$ \\
& $p=0.112$ & $p=0.000^{* * *}$ & 0.024 \\
\hline Effect Size $\left(\eta^{2}\right)$ & 0.015 & 0.045 & $($ significant differences among fields of study) \\
\hline \multicolumn{2}{|c|}{$* p<0.05 ; * * p<0.01 ; * * * p<0.001$} & & \\
\hline
\end{tabular}

Environmental studies majors showing significantly stronger beliefs about global disparities is consistent with a larger study by Canney and Bielefeldt [12] that assessed various dimensions of social responsibility as expressed by students in different engineering fields. In the Canney and Bielefeldt study, environmental engineering students reported higher scores than mechanical engineering students in dimensions of social responsibility associated with personal social awareness (recognition that other people need help and that one has both the ability as well as a moral obligation to help those who are in need), professional connectedness (moral obligation to serve others as an engineer, costs and benefits of socially responsible behavior), and analysis (recognizing that engineering design should consider social issues) [12]. In our study, environmental studies majors reported higher scores than engineering students in beliefs about global disparities scale. The higher levels of social responsibility indicated by both studies strongly suggest that the differences are not driven by engineering discipline but rather by the emphasis on the environment within major. Our results are also consistent with other STEMwide studies in which being an engineering major negatively predicts social agency [19]. 
Overall, business majors were very similar to engineering majors in beliefs about global disparities, social justice, and technology's capacity to address global issues. No significant differences were found in post-hoc comparisons between engineering and business majors on any of these scales.

Results for one-way ANOVAs for the three sustainability measures: beliefs, knowledge, and responsibility are summarized in Table 5. Significant differences among the four fields of study were found for all three sustainability measures, although effect sizes ranged between from 0.024 and 0.047 (i.e. between small and medium). Post-hoc comparisons using Bonferroni correction indicated that the mean score for knowledge of sustainability for environmental studies majors was significantly higher than engineering, education, and business majors. Environmental studies majors also reported a higher mean score for beliefs regarding sustainability, although the strength of the difference was considerably smaller than for sustainability knowledge. And, environmental studies majors reported significantly greater responsibility for sustainability than education and business majors but not compared to engineering majors. Post-hoc comparisons also indicated that engineering majors reported significantly greater responsibility scores than business majors.

Table 5: Descriptive Statistics for Sustainability Measures

\begin{tabular}{|c|c|c|c|}
\hline \multirow{2}{*}{ Type of Major } & \multicolumn{3}{|c|}{ Mean (SD) } \\
\hline & Beliefs & Knowledge & Responsibility \\
\hline All & $\begin{array}{c}N=399 \\
24.6(4.13)\end{array}$ & $\begin{array}{c}N=395 \\
15.7(3.16)\end{array}$ & $\begin{array}{c}N=397 \\
20.9(4.85)\end{array}$ \\
\hline Business & $\begin{array}{c}N=86 \\
24.6(5.3)\end{array}$ & $\begin{array}{c}N=84 \\
15.1(3.15)\end{array}$ & $\begin{array}{c}N=86 \\
19.6(5.44)\end{array}$ \\
\hline Education & $\begin{array}{c}N=40 \\
24.7(3.73)\end{array}$ & $\begin{array}{c}N=40 \\
15.0(3.46)\end{array}$ & $\begin{array}{c}N=40 \\
19.4(5.39)\end{array}$ \\
\hline Engineering & $\begin{array}{c}N=233 \\
24.3(3.83)\end{array}$ & $\begin{array}{c}N=233 \\
15.8(3.06)\end{array}$ & $\begin{array}{c}N=233 \\
21.2(4.53)\end{array}$ \\
\hline Environment & $\begin{array}{c}N=40 \\
24.7(3.73)\end{array}$ & $\begin{array}{c}N=38 \\
17.2(3.03)\end{array}$ & $\begin{array}{c}N=38 \\
23.1(3.55)\end{array}$ \\
\hline Maximum Score & 30 & 25 & 30 \\
\hline Minimum Score & 6 & 5 & 6 \\
\hline ANOVA Results & $\begin{array}{c}\mathrm{F}(3,393)=3.29 \\
p=0.021^{*}\end{array}$ & $\begin{array}{c}\mathrm{F}(3,393)=6.61 \\
p=0.000 * * *\end{array}$ & $\begin{array}{c}\mathrm{F}(3,391)=4.71 \\
p=0.003 * *\end{array}$ \\
\hline Effect Size & 0.024 & 0.047 & 0.035 \\
\hline
\end{tabular}

\section{Research Question \#2:}

How do what students believe and what they know about critical issues in global sustainability predict their sense of responsibility for global sustainability?

To answer this question, a hierarchical linear regression model was constructed with area of study (encoded in three effect coded variables as shown in Table 3) at the first level, the four belief scales and one knowledge scale at the second level, and any potentially significant 
interactions in the third level of the model. The dependent variable was responsibility for sustainability, a scale that measured a student's sense of personal and professional responsibility for addressing sustainability issues during life and career.

Results of the regression analysis are summarized in Table 6. In the first level model, being a business major and being an environmental studies major significantly predicted responsibility for sustainability. The first level model, however, was weak $\left(r^{2}=0.048\right)$. The second level model added the five subscales of social responsibility and sustainability, strengthening the model $\left(r^{2}=0.488\right)$ and eliminating the significance of being a business major and environmental major as predictors of responsibility for sustainability. A third level model added interactions between being a business major and the five variables in Model 2, between being an environmental studies major and the five variables in Model 2, and between beliefs about social justice and beliefs about sustainability. None of these interactions were significant in the third level model and are therefore not reported.

Table 6: Hierarchical Regression Models (Responsibility for Sustainability)

\begin{tabular}{|c|c|c|c|c|c|c|}
\hline \multirow[t]{3}{*}{ Predictor Variable } & & \\
\hline & \multicolumn{6}{|c|}{ Unstandardized Coefficient B (Standard Error) } \\
\hline & $\mathrm{B}(\mathrm{SE})$ & $p$ & & $\mathrm{~B}(\mathrm{SE})$ & $p$ & \\
\hline Constant & $20.9(0.30)$ & 0.000 & $* * *$ & $0.76(1.79)$ & 0.670 & \\
\hline Business & $-0.92(0.46)$ & 0.045 & $*$ & $-0.46(0.37)$ & 0.219 & \\
\hline Education & $-1.51(0.59)$ & 0.011 & $*$ & $-1.11(0.48)$ & 0.021 & $*$ \\
\hline Environment & $2.11(0.60)$ & 0.000 & $* * *$ & $0.72(0.49)$ & 0.146 & \\
\hline Beliefs: Global Disparities & & & & $-0.03(0.07)$ & 0.675 & \\
\hline Beliefs: Social Justice & & & & $0.29(0.10)$ & 0.004 & $* *$ \\
\hline Beliefs: Role of Technology & & & & $-0.06(0.09)$ & 0.501 & \\
\hline Beliefs: Sustainability & & & & $0.37(0.06)$ & 0.000 & $* * *$ \\
\hline Knowledge: Sustainability & & & & $0.55(0.07)$ & 0.000 & $* * *$ \\
\hline $\mathrm{r}^{2}$ & 0.048 & & & & & \\
\hline
\end{tabular}

Being an education major significantly and negatively predicted responsibility for sustainability and sustainable development, but did so with little model strength (low $\mathrm{r}^{2}$ ). This result may imply that education majors felt less responsible for addressing global scarcity, climate change, sustainable energy, or waste electronics either as consumers or professionals in their chosen career. Given the importance of these global issues, the fact that education majors are less likely to carry concerns for these critical issues into their classrooms than other professionals in their workplaces is worrisome. It is often said that sustainable behavior and habits begin early in life. Integrating these concerns into K-12 teaching is an essential part of helping college students to become attentive to and active in social and environmental responsibility. 
With regard to existing beliefs and knowledge, it is not surprising that this model showed that beliefs in sustainability and knowledge of sustainability topics significantly predicted responsibility for sustainable behavior in individuals' professional and personal lives. Believing that such issues as global scarcity impacted sustainability predicted that individuals felt responsible for addressing global resource scarcity in their careers. Likewise, knowing a great deal about topics such as global resource scarcity predicted a willingness and responsibility to do something about it. This is good news for higher education curricula, as building content knowledge may cause students to feel more responsible for critical global issues, either as professionals, consumers, or both. Since this is a cross-sectional study, however, we cannot confirm such a cause-and-effect relationship, and a future longitudinal study would help to solidify such a relationship if it exists.

More general beliefs regarding social justice also predicted a sense of responsibility for addressing specific critical issues of sustainability (e.g. resource scarcity, sustainable energy). The social justice scale included beliefs that no single country should dominate or exploit others, that the needs of the world's most fragile people are pressing, and that Americans should emulate sustainable and equitable behaviors of other countries. This result suggests that a broader belief in the need for greater social justice in the world leads to responsibility to play a role in addressing such issues through more sustainable development.

\section{Limitations and Implications}

Limitations: Although our research has provided additional evidence regarding differences between engineering students' perspectives vs. students in other majors, this study has limitations. The data is limited to a single institution and to primarily mechanical and electrical engineering majors, and the findings may not generalize to other engineering disciplines or to institutions of higher education other than the institution included in this study. While the study participants were chosen to represent a broad range of areas, there may be some self-selection bias among those who chose to complete the survey that has distorted the results. However, since the results of this research are consistent with previous studies, some of which involve much larger sample sizes across multiple institutions, the likelihood that self-selection bias and single institution focus have compromised the accuracy and generalizability of the results is low. Nevertheless, further research should be attentive to these issues to increase generalizability and reduce bias of the research.

Another limitation of this study is that it measures students' sense of responsibility for global sustainability at an individual level rather than at the level of the profession. Many of the most pressing social challenges that the world faces today, including sustainability, must be addressed collectively and it might be argued that taking individual responsibility for these issues is counterproductive. Thus, future studies should address student's obligations to be socially responsible both as individuals and as members of a larger collaborative community within their chosen profession.

A final limitation of the study centers on the data. The participant responses were gathered at one point in time, which means the relationships are based on concurrent responses. As such, the direction of effects between variables cannot be fully determined. While we do know that beliefs and motivation generally lead to action or responsibility, action or responsibility can also 
influence beliefs and motivation. Longitudinal research is needed to fully explore the direction of these effects.

Implications: The results of Research Question \#1 imply, in combination with other studies which have produced similar results across different disciplines, that engineers may be less concerned about social issues than professionals in other disciplines. However, differences in perceptions of and concerns for the social good within engineering, particularly between disciplines that have a heavy environmental focus (e.g. civil and environmental engineering and petroleum engineering) and those that do not (e.g. many mechanical and electrical engineering programs) suggest that this conclusion may be true for some engineering disciplines but not others.

The fact that business majors in this study reported similar beliefs to engineering majors suggests that reduced beliefs about global disparities and social justice extend beyond engineering and should be addressed more at a general education level. The good news, overall, is that this study suggests that stronger beliefs and knowledge may lead to greater professional and personal responsibility. If this relationship were confirmed in a longitudinal study, it could have strong implications for the benefits of including more content knowledge associated with critical sustainability topics and social issues in engineering curricula.

\section{Concluding Remarks}

This study has confirmed previous results that engineering students are different in several ways from those in other disciplines. The engineering population studied here, consisting primarily of mechanical and electrical engineers, had weaker beliefs about global disparities than those majoring in education and environmental studies. At a cross-sectional level, this study has also shown that beliefs and knowledge are strongly associated with and predict personal and professional responsibility for a more sustainable world. Future work should evaluate these results in the context of a larger and a more longitudinal study. Nevertheless, the results presented here offer strong support for including more engineering challenges that embrace social responsibility in the undergraduate engineering curriculum.

\section{Acknowledgments}

The authors would like to gratefully acknowledge the National Science Foundation for their support of this work under the TUES program (grant number DUE-1245464). Any opinions, findings, and conclusions or recommendations expressed in this material are those of the author(s) and do not necessarily reflect the views of the National Science Foundation.

\section{References}

[1] National Academy of Engineering, "Grand Challenges - 14 Grand Challenges for Engineering," 03-Feb-2019. [Online]. Available:

http://www.engineeringchallenges.org/challenges.aspx. [Accessed: 03-Feb-2019].

[2] P. Palazolo, S. Ivey, and C. Camp, "Freshman engineering student perceptions of engineering disciplines," in ASEE Southeast Section Annual Conference, Blacksburg, Virginia, 2010. 
[3] R. Stevens et al., Enabling Engineering Student Success: The Final Report for the Center for the Advancement of Engineering Education. San Rafael, CA: Morgan \& Claypool, 2010.

[4] C. E. Brawner, S. M. Lord, and M. W. Ohland, "Undergraduate women in chemical engineering: exploring why they come," in Proc., ASEE Annual Conference, Vancouver, British Columbia, 2011.

[5] J. J. VanAntwerp and D. Wilson, "Differences in Motivation Patterns Among Early and MidCareer Engineers," J. Women Minor. Sci. Eng., vol. 24, no. 3, pp. 227-259, 2018.

[6] M. Plett, C. Hawkinson, J. J. VanAntwerp, D. Wilson, and C. Bruxvoort, "Engineering identity and the workplace persistence of women with engineering degrees," in Proc., ASEE Annual Conference and Exposition, Vancouver, British Columbia, 2011.

[7] K. Buse, "Why They Stay: Individual Factors Predicting Career Commitment for Women Engineers," in Proc., The First International Conference on Engaged Management Scholarship, 2011.

[8] J. VanAntwerp and D. Wilson, "Difference Between Engineering Men and Women: How and Why They Choose What They Do During Early Career," in Proc., ASEE Annual Conference and Exposition, Seattle, Washington, 2015, pp. 26-543.

[9] National Academy of Engineering, Changing the Conversation: Messages for Improving Public Understanding of Engineering. Washington, DC: The National Academies Press, 2008.

[10] PEW Research Center, "Public Esteem for Military Still High | Pew Research Center," 11Jul-2013. [Online]. Available: http://www.pewforum.org/2013/07/11/public-esteem-formilitary-still-high/. [Accessed: 16-Mar-2019].

[11] D. B. Morais and A. C. Ogden, "Initial development and validation of the global citizenship scale," J. Stud. Int. Educ., vol. 15, no. 5, pp. 445-466, 2011.

[12] N. E. Canney and A. R. Bielefeldt, "Differences in engineering students' views of social responsibility between disciplines," J. Prof. Issues Eng. Educ. Pract., vol. 141, no. 4, pp. 110, 2015.

[13] E. A. Cech, "Culture of Disengagement in Engineering Education?," Sci. Technol. Hum. Values, vol. 39, no. 1, pp. 42-72, 2014.

[14] B. L. Yoder, "Engineering by the Numbers, 2015-2016." [Online]. Available: https://www.asee.org/documents/papers-and-publications/publications/collegeprofiles/16Profile-Front-Section.pdf.

[15] B. L. Yoder, “Engineering by the Numbers, 2014-2015.” [Online]. Available: https://www.asee.org/papers-and-publications/publications/collegeprofiles/15EngineeringbytheNumbersPart1.pdf.

[16] L. Berényi and N. Deutsch, "Gender Differences in Attitudes to Corporate Social Responsibility Among Hungarian Business Students,” Wseas Trans. Bus. Econ., vol. 14, 2017.

[17] R. Reis, M. von Schwedler, and S. Gomez, "Corporate social responsibility knowledge in higher education students in Portugal," in Proceedings of the 16th European Conference on Knowledge Management, 2015, pp. 628-634.

[18] M. A. Tarrant, D. L. Rubin, and L. Stoner, "The added value of study abroad: Fostering a global citizenry," J. Stud. Int. Educ., vol. 18, no. 2, pp. 141-161, 2014.

[19] J. C. Garibay, "STEM students' social agency and views on working for social change: Are STEM disciplines developing socially and civically responsible students?," J Res Sci Teach, vol. 52, no. 5, pp. 610-632, 2015. 
[20] J. C. Garibay, "Beyond Traditional Measures of STEM Success: Long-Term Predictors of Social Agency and Conducting Research for Social Change," Res. High. Educ., vol. 59, no. 3, pp. 349-381, May 2018.

[21] World Commission on Environment and Development, "Report of the World Commission on Environment and Development: Our Common Future." [Online]. Available: http://www.un-documents.net/our-common-future.pdf.

[22] (UNCED) United Nations Conference on Environment and Development, "United Nations Conference on Environment and Development (UNCED), Earth Summit," UN Sustainable Development Goals Knowledge Platform, 03-Feb-2019. [Online]. Available: https://sustainabledevelopment.un.org/milestones/unced. [Accessed: 03-Feb-2019].

[23] W. M. Adams, "The Future of Sustainability: Re-thinking Environment and Development in the Twenty-first Century," IUCN (The World Conservation Union). [Online]. Available: https://cmsdata.iucn.org/downloads/iucn_future_of_sustanability.pdf.

[24] A. Thatcher, "Theoretical definitions and models of sustainable development that apply to human factors and ergonomics," in Proc., Human Factors in Organizational Design and Management XI, Nordic Ergonomics Society Annual Conference, 2014, p. 6.

[25] S. Burian, "Teaching sustainability and sustainable engineering practice in the civil engineering curriculum," in ASEE Annual Conference and Exposition, Louisville, Kentucky, 2010 .

[26] D. M. Wilson and M. J. Kim, "Do Engineering Students View Sustainability Differently from Students in Other Majors?," Int. J. Eng. Educ., vol. 34, no. 6, pp. 1976-1986, 2018.

[27] T. P. Seager and E. Selinger, "Experiential teaching strategies for ethical reasoning skills relevant to sustainability," in IEEE International Symposium on Sustainable Systems and Technology, Phoenix, Arizona, 2009.

[28] D. Braun, "Teaching Sustainability Analysis in Electrical Engineering Lab Courses," IEEE Trans. Educ., vol. 53, no. 2, pp. 243-247, May 2010.

[29] R. Roberts, "Evaluating Psychographic Measures among Undergraduates: Relevance to Marketing of Sustainable Tourism," M.S. Thesis, University of Washington, 2015.

[30] R. Roberts and D. Wilson, "Cross-Validation of a Global Citizenship Scale: Constructs for Evaluating Undergraduate Engineering Perspectives," in Proc., ASEE Annual Conference and Exposition, New Orleans, Louisianna, 2016.

[31] J. Cohen, “The effect size index: d," Stat. Power Anal. Behav. Sci., vol. 2, pp. 284-288, 1988. 